\title{
Adaptation of orchestration graphs in gamification
}

\author{
Tomasz Lipczyński \\ West Pomeranian University of \\ Technology ul. Żołnierska 49, \\ $71-210$ \\ Szczecin, Poland \\ Email: tlipczynski@wi.zut.edu.pl
}

\author{
Magdalena Kieruzel \\ West Pomeranian University of \\ Technology ul. Żołnierska 49, \\ $71-210$ \\ Szczecin, Poland \\ Email: mkieruzel@wi.zut.edu.pl
}

\author{
Przemysław Różewski \\ West Pomeranian University of \\ Technology ul. Żołnierska 49, \\ $71-210$ \\ Szczecin, Poland \\ Email:prozewski@wi.zut.edu.pl
}

\begin{abstract}
The term gamification is a relatively new concept, but the use of games for solving a variety of problems is not a new phenomenon. Gamification is used in many industries such as marketing, politics, health, eniviroment. In education, gamification) is used as a tool to strengthen e-learning systems, motivate students to learn more effectively and engage more in the learning process. Moreover, games provides new insight on learning materials

The concept of orchestration is defined by methods that allow the management of educational activities in such a way that a pedagogical effect is achieved. Orchestration relies on graphs that describe educational scenarios from different viewpoints structure of activities, pedagogical ideas, workflow.

The main aim of the article is to show the possibilities of orchestration graphs as a tool for supporting gameducation.
\end{abstract}

\section{INTRODUCTION}

Gamification is the use of mechanics known from roleplaying and computer games to modify people's behavior in non-gaming situations to increase their engagement [1][2]. Technique is based on the pleasures that come from pursuing the next achievable challenge, competition, collaboration, etc. Creation allows people to engage in activities that are in line with the author's expectations, even if they are considered boring or routine [3]. The method is mainly used in marketing, science/training, market research and in motivating the company's employees [4]. Although the use of rewards, loyalty programs, and game schema elements has been used in business for a long time, the gamification itself has been described and detailed in the United States only in 2010. Then they began to appear websites such as Bunchball and Badgeville, which introduced elements familiar from games to their sites in order to diversify and attract customers.

Dillenbourg and others define the process of orchestration as a real-time management of multi-layered activities in a multiconstraints context[11]. Orchestration graph visualizes the teaching scenario consisting of learning activities [12]. Dillenbourg uses orchestration graphs in most cases as a tool to facilitate the functioning of the Massive Open Online Courses (MOOC) [13].
In this article we would like to propose a different form to use it - as a tool to support gamification.

\section{THE ESSENCE OF GAMIFICATION}

Education using a game methodology is a new field, but the games themselves are involved in the life of mankind since the dawn of time. Motivation and engagement are usually seen as a prerequisite for completing a task or encouraging a particular behavior.

At this point we should explain differences between gamification and serious games There are some terms and concepts that have similarities - gamification, game inspired design, serious games, simulations and games. The boundaries between them are not clearly defined [5]:

- Game inspired design is the use of ideas and ways of thinking that are inherent in games. Game inspired design does not express in adding game elements, but rather in using of playful design.

- Gamification is the use of game metaphors, game elements and ideas in a context different from that of the games in order to increase motivation and commitment, and to influence user behavior.

- Serious games are games designed for a specific purpose related to training, not just for fun. They possess all game elements, they look like games, but their objective is to achieve something that is predetermined.

- Simulations are similar to serious games, but they simulate real-world things and their purpose is user training in an environment resembling real life.

- Games include everything mentioned above and they are designed for entertainment.

All the above-mentioned concepts have one thing in common - they use elements that are inherent in games and their purpose is to support learning and to improve users' engagement.

In education, the main causes of poor performance are boredom, lack of commitment, and deconcentration caused by widespread access to new mobile technologies [6].

Effective game must have a clear goal, constant feedback messages, the pleasure of achieving small victories, winning small artifacts, the company of other participants in the game 
[7]. While the concept of gamification may be simple, effectively gamifying a concept isn't. However, it can be simplified, by following a five-step process.

\section{Understanding the target audience and the context}

The decisive factor for the success of the educational program is appropriate recognition to whom it is addressed. This combined with the context in which the program is being delivered, will help in designing a program that empowers the student to achieve the objective of the program. Audience analysis can help you determine factors such as age, skills, and knowledge, analysis of the context can provide detailed information on the size of the group of students, the environment, determining skill and timing.

\section{Defining learning objectives}

Defining educational objective is based on the answer to what a student will achieve by implementing an educational program. These goals can be divided into three groups:

- General Instructional Goals such as having the student complete an assignment, a test/quiz/exam, a project, etc.

- Specific Learning Goals which could include the student understanding a concept, being able to perform a task after the training, or completing the learning program.

- Behavioral Goals which may require the student to concentrate in class, complete assignments faster, minimize distractions in class, etc.

\section{Sequence learning process}

Structuring the experience via stages and milestones enable instructors to sequence knowledge and quantify what the students need to learn and achieve by the end of each stage or milestone. These milestones work well for students as well, as it makes the ultimate objective seem more achievable and measurable, while ensuring that obstacles within and between each stage are easily identifiable. Breaking down the education program into different stages gives the instructor the opportunity to judge the objectives, context, and pain points, and prepare a more effective overall gamified process for education.

\section{Defining game elements}

After identification of stages and milestones we can decide which stages, if any, can be gamified, and how. Considering the gamification we should answer the following questions:

- can we apply tracking mechanism?

- what currency we would use and how much we need to level-up?

- are the implemented rules transparent to participants?

- does the overall system give the student and/or instructor feedback?

When designing the section being gamified, a currency can help determine levels within a stage and it is possible for a level to be a whole stage in the education program. It also gives the instructor the opportunity to use currency-based levels and rules to receive and give feedback. Feedback is an important ally, as studies show that students do better when given more opportunities to complete a task [8]. This is exactly what makes games appealing, as students are given quick feedback if they do a task wrong and have the chance to try it again.

\section{Applying game elements in education}

Gamification in education is based on the implementation of game elements into the teaching content. Game mechanics can be classified as self-elements or social-elements [9].

Self-elements can be points, achievement badges, levels, or simply time restrictions. These elements get students to focus on competing with themselves and recognizing selfachievement. Social-elements on the other hand, are interactive competition or cooperation, like for example leaderboards. These elements put the students in a community with other students, and their progress and achievements are made public.

Keeping other factors constant, social-elements can motivate students in a community setting.

Applying gamification strategies and/or technology to curriculums may often do a better job of teaching. However, it does not mean it should be a replacement for a comprehensive curriculum or face-to-face instruction. Instructors must be careful not to depend on extrinsic motivators in the game to modify student behaviour, as the habit created during the gamified process may not sustain once the extrinsic reward is gone [10].

\section{CONCEPT OF ORCHESTRATION}

The term orchestration can be defined as real time management of multilayered activities in a multi-constraints context [13]. The concept of orchestration defines the role of the teacher as a person defining the forms of student interaction, management of available resources and technology.

In 2015, Dillenbourg [11] introduced the idea of orchestration graphs (fig.1) in the form of timelines with social granularity on the y-axis (ranging from individual work, to small groups, whole class, and the world) and time along the $\mathrm{x}$-axis (fig.1). It is a structured view of a learning scenario, consisting of learning activities (nodes). Activities take place at different social planes, have a start and an endtime.

On an individual plan students work independently on the assigned task(gathering information, writing summary, reading text, etc.).

On the set of group students work in small teams (up to 10 people) focused on solving a given problem.

Within the team, individuals may be assigned different roles, but, at the end, they need to converge on a joint product.

On the class plane, the activity involves all the students in the class: they do activities such as listening to lectures, participating in discussions, presenting posters, or visiting a museum together. 


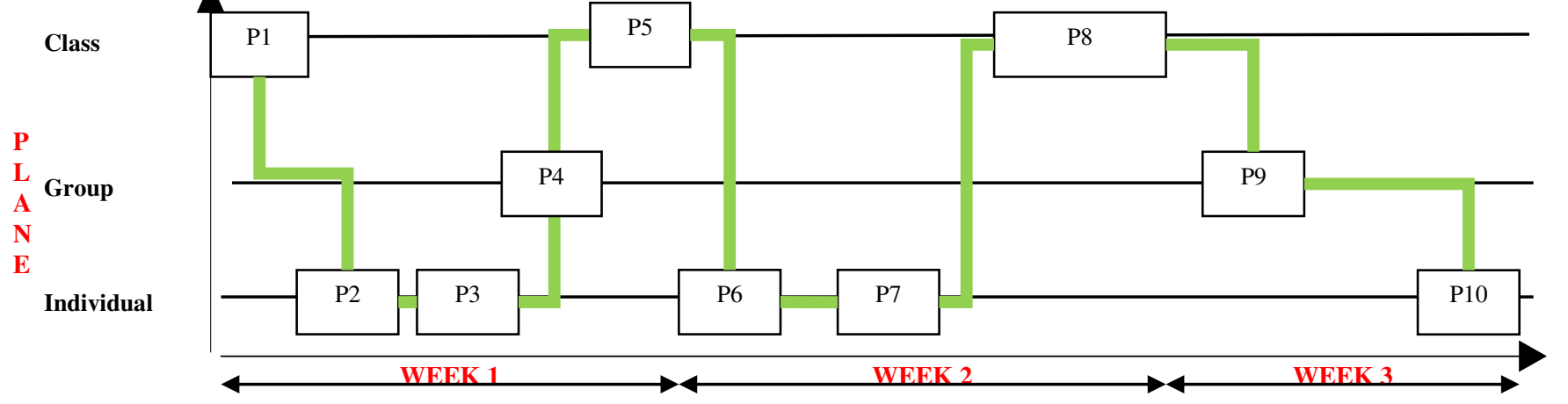

TIME

Fig.1 Example of orchestration graph.

The term activity defines what students should do to achieve the goal established by the teacher. Activities do not have a specific duration, can last 2 seconds or 2 months. Some activities performed by learners cannot strictly be qualified as "learning activities" - students are not exactly learning anything, but they have to perform an activity required for continuing the learning scenario(i.e. finding teammates). Therefore term "learning activity" can be considered as synonymous with "learner activity" [11].

Activities can be described by parameters such as:

- objects

- products

- competencies

- traces

- metadata.

In orchestration graphs, activities are connected by edges.

These can contain pedagogical justifications (e.g., activity 1 is an advanced organiser for activity 2), learning analytics information (e.g., student success is activity 1 is $34 \%$ correlated with/predictive of success in activity 2), and operators [13].

Operators receive data from student activities (products), and generate input for subsequent activities. Operations can include aggregation, disaggregation, assignment, translation and transformation of the student product. Operators are also used to generate social structures based on input data, such as organizing students into groups based on their previous answers [12].

Operators are classified into categories [12]:

- Aggregation operators gather data for subsequent activities (listing, classifying, sorting, synthesizing, visualizing),

- Distribution operators split data for subsequent activities (broadcasting, user selection, sampling, splitting, conflicting, adapting),

- Social operators modify the social structure of activities (group formation, class split, role assignment, role rotation, group rotation, dropout management, anonymization),

- Back-office operators enrich data with external information, including information manually provided by human actors (grading, feedback, anti-plagiarism, rendering, translating, summarizing, converting, updating).
In gamification you may attempt to use the following operators which capture the spirit of the game: real time feedback, tracking mechanism, leveling, currency, teaming, plot twisting, loss aversion, challenges, discovery and exploration, countdown.

The use of graphs and operators to illustrate the implementation of games in education will be presented in the next section.

\section{POSSIBILITY OF USING ORCHESTRATION GRAPHS IN GAMIFICATION}

In order to judge the effectiveness of gamification scientists of University of Cape Town (UCT) decided to apply it to an existing Computer Science course focusing on 2D games design and development a traditional computer game [14]. The game had a Steampunk theme. Steampunk is a science fiction sub-genre set in an alternate past similar to the Victorian era, but with advanced technology. Students are introduced to a secret "Order of the Curmudgeons". This order is a club of mad scientists, each with their individual quirks and expertise. A device called the "Crowther Engine" has gone missing and the students must solve the mystery of its theft. This is accomplished by earning clues by completing tasks. Once the students unravel the final set of clues, they have solved the mystery.

The long-term goals of the second year Games Course are to teach development concepts and skills relevant to $2 \mathrm{D}$ games design. Gamification is intended to aid in meeting this longterm goal by [14]: improving the students review of course material, increasing meaningful class participation, fostering problem solving skills, increase lecture attendance,encouraging creativity in practical tasks.

Each of these sub-goals in design was linked explicitly to a reward structure, through an experience point (XP) system. The students were given short timed assessments, in the form of quizzes, once a week. The quizzes were based on lecture material taught in the previous week and promoted a review of course material after lectures. Students were awarded experience points (XP) for achieving various levels of success: 10 XP were given for $70-79 \%$, 20XP for $80-89 \%$, 30XP for $90-100 \%$. 




P1 - lecture P2 - first weekly quiz

P3 - first weekly puzzle P4 - group challenge

P5 - lecture and feedback P6 - weekly quiz

P7 - weekly puzzle P8 - lecture and feedback

P9 - group challenge P10 - weekly quiz

Fig.2 Orchestration graph with operators

Sporadic group challenges were organised throughout the semester to practice game development concepts learnt in class.

The above mentioned activities can be visualized using orchestration graphs (fig 2).

As you can see above operators fit into the framework of the previously described ones. Operator 1 and 2 contains operators(mentioned in chapter III) such as leveling, challenge, countdown, loss aversion(not getting a reward, but avoiding punishment).

By using graphs we can accurately plan student behavior, enhance all educational-related factors - participation in lectures (gaining extra points), group work (brainstorm to overcome difficult challenges), knowledge exchange ( to shorten task execution time).

\section{CONCLUSION}

So far orchestration graphs have been used as a tool to support the functioning of MOOC [12]. We want to propose to use them in gamification, which is a one of the educational approaches and techniques that increase motivation and engagement of learners [15].

Use of orchestration graphs can open new opportunities for support of development of an effective strategy for the implementation of gamification in e-learning.

\section{REFERENCES}

[1] J. Hamari, J. Koivisto, H. Sarsa, "Does gamification work? - A literature review of empirical studies on gamification," in Proc. 47th Hawaii Int. Conf. Syst. Sci., 2014, pp. 1-10. https://doi.org/10.1109/HICSS.2014.377

[2] S. Deterding, D. Dixon, R. Khaled, and L. Nacke, "From game design elements to gamefulness: defining gamification", In Proceedings of the 15th International Academic MindTrek Conference: Envisioning Future Media Environments, September 2830, 2011, Tampere, Finland, ACM, pp. 9-15. http://dl.acm.org/citation.cfm?doid=2181037.2181040
[3] C.S. Deterding, M. Sicart, L. Nacke, K. O’Hara, D. Dixon "Gamification: Using Game Design Elements in Non-Game Contexts". In CHI 2011 Workshop Gamification: Using Game Design Elements in Non-Game Contexts, Vancouver, Canada, 2011, p.2-5. https://doi.org/10.1145/1979742.1979575

[4] G. Zichermann ,J. Linder, "The Gamification Revolution. How Leaders Leverage Game Mechanics to Crush the Competition", McGraw Hill Education, New York 2013

[5] G. Kiryakova, N. Angelova, L Yordanova "Gamification in education" Proceedings of 9th International Balkan Education and Science Conference Edrine, Bulgaria, 2014, p.293.

[6] M. Richtel,. "Growing Up Digital, Wired for Distraction". http://www.nytimes.com/2010/11/21/technology/21brain.html?pagew anted=all\&_r=2\& 2010.11. 21

[7] L.C. Wood,T. Reiners, "Gamification in logistics and supply chain education: Extending active learning". IADIS Internet Technologies and Society, Perth, Australia, 2012, 101-108.

[8] C.Evans, (2011, July 31). Game designer Jane McGonigal interviewed by Cameron Evans, U.S. Education CTO, Microsoft. (J. McGonigal, Interviewer) http://www.youtube.com/watch?v=5mc9Rrfs00

[9] G.Kovacs, Why to use gamification in higher education?, ICT for language learning 8th edition, Florence, Italy 2013, p.345.

[10] W. Hsin-Yuan Huang, D. Soman, A Practitioner's Guide To Gamification of Education, Rotman School of Management University of Toronto 2013, p. 11-16

[11] P. Dillenbourg, M. Nussbaum, Y. Dimitriadis, , J. Roschelle, Design for classroom orchestration. Computers \& Education, 69, 485-492. 2012 https://doi.org/10.1016/j.compedu.2013.04.013

[12] P. Dillenbourg, " Orchestration Graphs: Modeling scalable education". EPFL Press 2015.

[13] S. Håklev, L. Faucon, T. Hadzilacos, P. Dillenbourg, Orchestration Graphs: Enabling Rich Social Pedagogical Scenarios in MOOCs, L@S 2017, the Fourth Annual Meeting of the ACM Conference on Learning at Scale 2017 p.262

[14] S. O'Donovan, J. Gain, P. Marais, "A case study in the gamification of a university-level games development course", SAICSIT '13 Proceedings of the South African Institute for Computer Scientists and Information Technologists Conference p.246-248, 2013 https://doi.org/10.1145/2513456.2513469

[15] J.J. Lee, J. Hammer, "Gamification in Education: What, How, Why Bother?" Academic Exchange Quarterly, 2011, 15(2). 